\title{
Improved insulin sensitivity and adipose tissue dysregulation after short-term treatment with pioglitazone in non-diabetic, insulin-resistant subjects
}

Received: 16 July 2004 / Accepted: 14 September 2004 / Published online: 29 December 2004

C) Springer-Verlag 2004

\begin{abstract}
Aims/hypothesis: We examined whether shortterm treatment with a thiazolidinedione improves insulin sensitivity in non-obese but insulin-resistant subjects and whether this is associated with an improvement in dysregulated adipose tissue (reduced expression of IRS1 , GLUT4, PPAR $\gamma$ co-activator 1 and markers of terminal differentiation) that we have previously documented to be associated with insulin resistance. Methods: Ten nondiabetic subjects, identified as having low IRS-1 and GLUT-4 protein in adipose cells as markers of insulin resistance, underwent 3 weeks of treatment with pioglitazone. The euglycaemic-hyperinsulinaemic clamp technique was used to measure insulin sensitivity before and after treatment. Serum samples were analysed for glucose, insulin, lipids, total and high-molecular-weight (HMW) adiponectin levels. Biopsies from abdominal subcutaneous adipose tissue were taken, cell size measured, mRNA and protein extracted and quantified using real-time RT-PCR and Western blot. Results: Insulin sensitivity was improved after 3 weeks treatment and circulating total as well as HMW adiponectin increased in all subjects, while no effect was seen on serum lipids. In the adipose cells, gene and protein expression of IRS-1 and PPAR $\gamma$ co-activator 1 remained unchanged, while adiponectin, adipocyte $\mathrm{P} 2$, uncoupling protein 2 , GLUT4 and liver $\mathrm{X}$ receptor- $\alpha$ increased. Insulin-stimulated tyrosine phosphorylation and p-ser-PKB/Akt increased, while no significant effect of thiazolidinedione treatment was seen on the inflammatory
\end{abstract}

\footnotetext{
A. Hammarstedt · V. Rotter Sopasakis · S. Gogg

P.-A. Jansson · U. Smith

The Lundberg Laboratory for Diabetes Research, Department of Internal Medicine, The Sahlgrenska Academy at Göteborg University,

Göteborg, Sweden

U. Smith $(\bowtie)$

The Lundberg Laboratory for Diabetes Research, Department of Internal Medicine, Sahlgrenska University Hospital,

41345 Göteborg, Sweden

e-mail: ulf.smith@medic.gu.se

Tel.: +46-31-3421104

Fax: $+46-31-829138$
}

status of the adipose tissue in these non-obese subjects. Conclusions/interpretation: Short-term treatment with pioglitazone improved insulin sensitivity in the absence of any changes in circulating NEFA or lipid levels. Several markers of adipose cell differentiation, previously shown to be reduced in insulin resistance, were augmented, supporting the concept that insulin resistance in these individuals is associated with impaired terminal differentiation of the adipose cells.

Keywords Adiponectin - Adipose tissue - GLUT4 . Insulin resistance $\cdot$ IRS-1 $\cdot$ LXR $\cdot$ Thiazolidinediones

Abbreviations AdipoR: Adiponectin receptor - aP2: Adipocyte P 2 - C/EBP: CCAAT/Enhancer binding protein - GIR: Glucose infusion rate - HMW: High molecular weight · IR: Insulin receptor - LBM: Lean body mass - LXR: Liver X receptor - MCP1: Monocyte chemoattractant protein-1 - PGC-1: PPAR $\gamma$ Co-activator 1 - PI3-kinase: Phosphoinositide-3-kinase - PKB: 3-Phosphoinositide-dependent protein kinase B - PPAR: Peroxisome proliferator-activated receptor - PTP: Phosphotyrosine phosphatase - SOCS: Suppressors of cytokine signalling - PTP-1C: Phosphotyrosine phosphatase 1C - RXR: Retinoic X receptor - UCP-2: Uncoupling protein 2

\section{Introduction}

Thiazolidinediones like pioglitazone and rosiglitazone are powerful insulin sensitisers used in the treatment of type 2 diabetes. The nuclear receptor for thiazolidinedione, peroxisome proliferator-activated receptor (PPAR) $\gamma$, is highly expressed in adipocytes suggesting that thiazolidinediones mainly exert their insulin-sensitising effect through the adipose tissue although controversial results have been published $[1,2]$. Thiazolidinediones improve insulin sensitivity both in man and in different animal models of insulin resistance $[3,4]$. The improvement in insulin resistance is, at least in rodent models, accompanied 
by a remodelling of the adipose tissue, where large adipocytes are replaced by an increased recruitment of small and more insulin-sensitive cells $[5,6]$. However, to what extent this occurs in human adipose tissue is still not clear [7].

The adipose tissue is an endocrine organ, secreting several factors (adipokines) that can affect whole-body insulin sensitivity. One such molecule of great current interest is adiponectin, which is only secreted by the adipose cells [8-10]. Thiazolidinediones not only increase the concentration of total circulating adiponectin but also alter the relative abundance of the different molecular weight complexes [11].

Growing evidence has pointed to a relationship between low-grade chronic systemic inflammation and insulin resistance. Studies in man have shown an increase in inflammatory markers and cytokines in different states of insulin resistance [12]. Recent studies have also shown that the adipose tissue becomes "inflamed" in obesity as a consequence of an increased infiltration of inflammatory cells [13-15]. Furthermore, the adipose tissue expression of macrophage-related genes is positively correlated with BMI and adipocyte cell size [13]. Similarly, we have recently shown that there is a correlation between fat cell size and IL-6 secretion in vitro as well as the interstitial concentrations in the adipose tissue in vivo [16].

We have also recently shown that there is a clear association between insulin resistance, type 2 diabetes and adipose tissue dysfunction. For instance, several key molecules for insulin signalling and action, such as IRS-1 and GLUT4, are reduced in adipose cells from insulinresistant subjects with or without type 2 diabetes [17, 18].

The insulin-stimulated activation of phosphoinositide-3kinase (PI3-kinase), phosphoinositide-dependent protein kinase $\mathrm{B}$ (PKB)/Akt and glucose transport in the adipose cells are also impaired in insulin-resistant states [17, 18]. In addition to these perturbations, we have identified other markers for dysregulated adipose tissue in insulin resistance suggesting impaired adipose cell differentiation, i.e. reduced expression of adiponectin and adipocyte $\mathrm{P} 2$ (aP2), low circulating adiponectin levels, increased fat cell size $[19,20]$ and a reduced expression of the PPAR $\gamma$ coactivator 1 (PGC-1) [21].

In the present study, we examined whether a 3-week treatment with the thiazolidinedione, pioglitazone, improves insulin sensitivity in insulin-resistant but non-obese and non-diabetic subjects exhibiting the markers of adipose tissue dysfunction and, if so, whether this is related to an improvement in these markers. In addition, we examined if the thiazolidinedione in this group changed the expression of inflammatory markers related to monocyte/macrophage infiltration in the adipose tissue.

\section{Materials and methods}

Subjects This study was approved by the Ethical Committee of Göteborg University and informed consent was obtained from each subject. Ten non-diabetic subjects, previously identified as having low expression of IRS-1 and GLUT4 protein in the adipose cells as markers of insulin resistance $[17,18]$, volunteered to undergo 3 weeks of treatment with pioglitazone (Actos, $30 \mathrm{mg} /$ day). Body weight and height were recorded with standard techniques. Waist and hip circumferences were measured as described [22] and WHR calculated. Lean body mass (LBM) was calculated from bioimpedance analysis (BIA-101, Akern, Florence, Italy) [23].

Euglycaemic-hyperinsulinaemic clamp Insulin sensitivity was measured with the euglycaemic-hyperinsulinaemic clamp technique [24], previously described in detail [25]. In brief, insulin was infused at a constant rate of 40 $\mathrm{mU} \cdot \mathrm{m}^{2} \cdot \mathrm{min}^{-1}$ into an intravenous cannula placed in the antecubital vein. By infusing glucose at a variable rate, blood glucose was maintained at $5 \mathrm{mmol} / \mathrm{l}$. Steady state was reached after $60-90 \mathrm{~min}$, and the average rate of glucose infusion required to maintain euglycaemia was calculated over the final $30 \mathrm{~min}(90-120 \mathrm{~min})$ and expressed per kilogram LBM. Glucose was analysed in venous blood using an automatic glucose analyser (Yellow Springs Instruments, Yellow Springs, OH, USA) and insulin with a standard radioimmunoassay (Amersham, Uppsala, Sweden).

Biochemical analyses Non-esterified fatty acids in serum were measured by an enzymatic colorimetric method (Wako Chemicals, Neuss, Germany) while other plasma lipid concentrations were determined with an automated Cobra Mira analyser (Hoffman-LaRoche, Basel, Switzerland) [26]. Circulating adiponectin levels were measured in plasma by an ELISA (B-Bridge International, Sunnyvale, CA, USA).

Velocity sedimentation of adiponectin Five to $20 \%$ sucrose gradients were poured stepwise in thin-walled ultracentrifuge tubes (Beckman, Palo Alto, CA, USA) and allowed to equilibrate overnight at $4^{\circ} \mathrm{C}$. Following layering of the sample on top, gradients were centrifuged at $55,000 \times \mathrm{g}$ for $4 \mathrm{~h}$ at $4^{\circ} \mathrm{C}$ in a TLS55 rotor in a Beckman TL-100 ultracentrifuge. 150- $\mu \mathrm{l}$ gradient fractions were sequentially retrieved and analysed by quantitative Western blot analysis as described below.

Fat cell isolation Human abdominal subcutaneous adipose tissue was obtained in the fasting state by a surgical incision. Isolation of human adipose cells was performed essentially as described previously [27]. Briefly, biopsies were washed to remove traces of blood and treated with $0.8 \mathrm{mg} / \mathrm{ml}$ collagenase (Sigma, St. Louis, MO, USA) for $\sim 60 \mathrm{~min}$ at $37^{\circ} \mathrm{C}$. Isolated adipose cells were filtered through a $250-\mu \mathrm{m}$ nylon mesh, washed four times with fresh medium to remove collagenase and the cell size was then measured [27].

Cell lysate and immunoblotting Isolated human adipocytes were separated from medium by centrifugation through dinonyl phthalate. Lysis buffer was added, samples briefly 
vortexed and rocked for $2 \mathrm{~h}$ at $4^{\circ} \mathrm{C}$. Detergent-insoluble material was sedimented through centrifugation at $12,000 \times g$; this was done for $10 \mathrm{~min}$ at $4^{\circ} \mathrm{C}$. Supernatants were collected and stored at $-80^{\circ} \mathrm{C}$ prior to use [17]. Protein concentration was measured using the bicinchonic acid method (Pierce, Rockford, IL, USA).

Lysate proteins were separated on SDS-PAGE as described [18] and immunoblotted with anti-adiponectin (Alexis, Lausen, Switzerland), anti-IRS-1, anti-IRS-2 (Upstate Biotechnology, Lake Placid, NY, USA), antiPGC-1, anti-phosphotyrosine (Santa Cruz, Santa Cruz, CA, USA), anti-PKB/Akt, anti-phospho-serine-PKB/Akt (p-ser-PKB/Akt) (Cell Signaling Technology, Beverly, MA, USA), anti-GLUT4 (Chemicon, Temecula, CA, USA) and anti-perilipin (PROGEN Biotech, Heidelberg, Germany) antibodies according to the manufacturer's recommendations.

Enhanced chemiluminescence was used to detect the proteins (Amersham, Buckinghamshire, UK). Band intensities were quantified using a Personal Densitometer (Molecular Dynamics, Sunnyvale, CA, USA) and analysed using ImageQuant software provided by the manufacturer.

$m R N A$ isolation and quantification Total cellular RNA was extracted with the guanidinium thiocyanate method as described [28] and TaqMan Real Time RT-PCR was used to quantify mRNA expression.

The RNA samples were treated with DNAse and singlestranded random-hexamer-primed cDNA was synthesised. Gene-specific probes and primer pairs were designed using Primer Express software (Applied Biosystems, Foster City, CA, USA). The quantification was performed using the standard protocol of ABI PRISM 7700 (Applied Biosystems). For each primer/probe set (available upon request), a standard curve was generated. Each sample was run in duplicate and the mean value was used to calculate mRNA levels. The quantity of a particular gene in each sample was normalised to that of $18 \mathrm{~s}$.

Statistical analysis Conventional statistical methods were used (Stat View; SAS Institute, Cary, NC, USA). Differ- ences were tested with two-tailed Student's $t$-test for paired comparison, with a $p$ value of less than 0.05 considered to be significant.

\section{Results}

Clinical characteristics and effect of thiazolidinedione The clinical characteristics of the subjects before and after treatment are shown in Table 1. The subjects were nonobese and neither body weight nor WHR changed during the treatment period. There were also no significant changes in fasting blood glucose or lipid levels after the treatment. Insulin sensitivity, measured with the hyperinsulinaemic-euglycaemic clamp technique, was improved by $20 \%$ after 3 weeks treatment $(p<0.01)$. This improvement was seen in all but one subject. Surprisingly, both fasting and NEFA levels during the clamp (180 min) were similar before and after thiazolidinedione treatment. Average fat cell size decreased in most subjects (Table 1). However, a decreased mean fat cell size was not a prerequisite for improved insulin sensitivity.

Circulating adiponectin levels increased by approximately $100 \%$ after thiazolidinedione treatment $(p<0.001$, Table 1, Fig. 1a) and, in contrast to the glucose infusion rate (GIR), all individuals increased their adiponectin levels. No significant correlation was seen between circulating adiponectin levels and the GIR before or after treatment with thiazolidinedione (Fig. 1c, e). Furthermore, there was no correlation between the increase in circulating adiponectin concentrations and the improvement in insulin sensitivity (data not shown).

We also measured the ratio between the high-molecular weight (HMW) adiponectin and the total amount of adiponectin. The relative amount of HMW adiponectin increased in all subjects after treatment (average increase $11 \% ; p<0.01$ ) (Fig. 1b). However, neither the levels before or after thiazolidinedione correlated significantly with whole-body insulin sensitivity, measured as GIR (Fig. 1d, f), nor did the absolute change following pioglitazone treatment (data not shown). Interestingly, there was no relationship between HMW adiponectin, or the increase
Table 1 Clinical characteristics and metabolic variables

Values are expressed as mean \pm SEM.

$T G$ Triglycerides, GIR glucose infusion rate

\begin{tabular}{lrrl}
\hline & Before treatment & After treatment & $p$ Value \\
\hline Age $($ years $)$ & $43.3 \pm 1.9$ & & \\
BMI $\left(\mathrm{kg} / \mathrm{m}^{2}\right)$ & $26.9 \pm 1.1$ & $26.9 \pm 1.0$ & $\mathrm{NS}$ \\
WHR & $0.95 \pm 0.01$ & $0.95 \pm 0.01$ & $\mathrm{NS}$ \\
f-Glucose $(\mathrm{mmol} / \mathrm{l})$ & $4.94 \pm 0.20$ & $4.65 \pm 0.16$ & 0.06 \\
f-Insulin $(\mathrm{mU} / \mathrm{l})$ & $9.39 \pm 1.32$ & $8.34 \pm 1.05$ & $\mathrm{NS}$ \\
f-HDL $(\mathrm{mmol} / \mathrm{l})$ & $1.39 \pm 0.10$ & $1.45 \pm 0.14$ & $\mathrm{NS}$ \\
f-Cholesterol $(\mathrm{mmol} / \mathrm{l})$ & $5.65 \pm 0.31$ & $5.57 \pm 0.25$ & $\mathrm{NS}$ \\
f-TG $(\mathrm{mmol} / \mathrm{l})$ & $1.78 \pm 0.29$ & $1.66 \pm 0.28$ & $\mathrm{NS}$ \\
NEFA baseline $(\mathrm{mmol} / \mathrm{l})$ & $0.53 \pm 0.03$ & $0.45 \pm 0.06$ & $\mathrm{NS}$ \\
NEFA $180 \mathrm{~min}(\mathrm{mmol} / \mathrm{l})$ & $0.11 \pm 0.02$ & $0.13 \pm 0.02$ & $\mathrm{NS}$ \\
GIR $\left(\mathrm{mg} \cdot \mathrm{kg} \mathrm{LBM} \mathrm{min}^{-1}\right)$ & $7.70 \pm 0.76$ & $9.17 \pm 0.92$ & $<0.01$ \\
Cell size $(\mu \mathrm{g})$ & $0.46 \pm 0.03$ & $0.42 \pm 0.04$ & $\mathrm{NS}$ \\
Adiponectin $(\mu \mathrm{g} / \mathrm{ml})$ & $7.16 \pm 1.36$ & $13.51 \pm 1.87$ & $<0.001$ \\
\hline
\end{tabular}



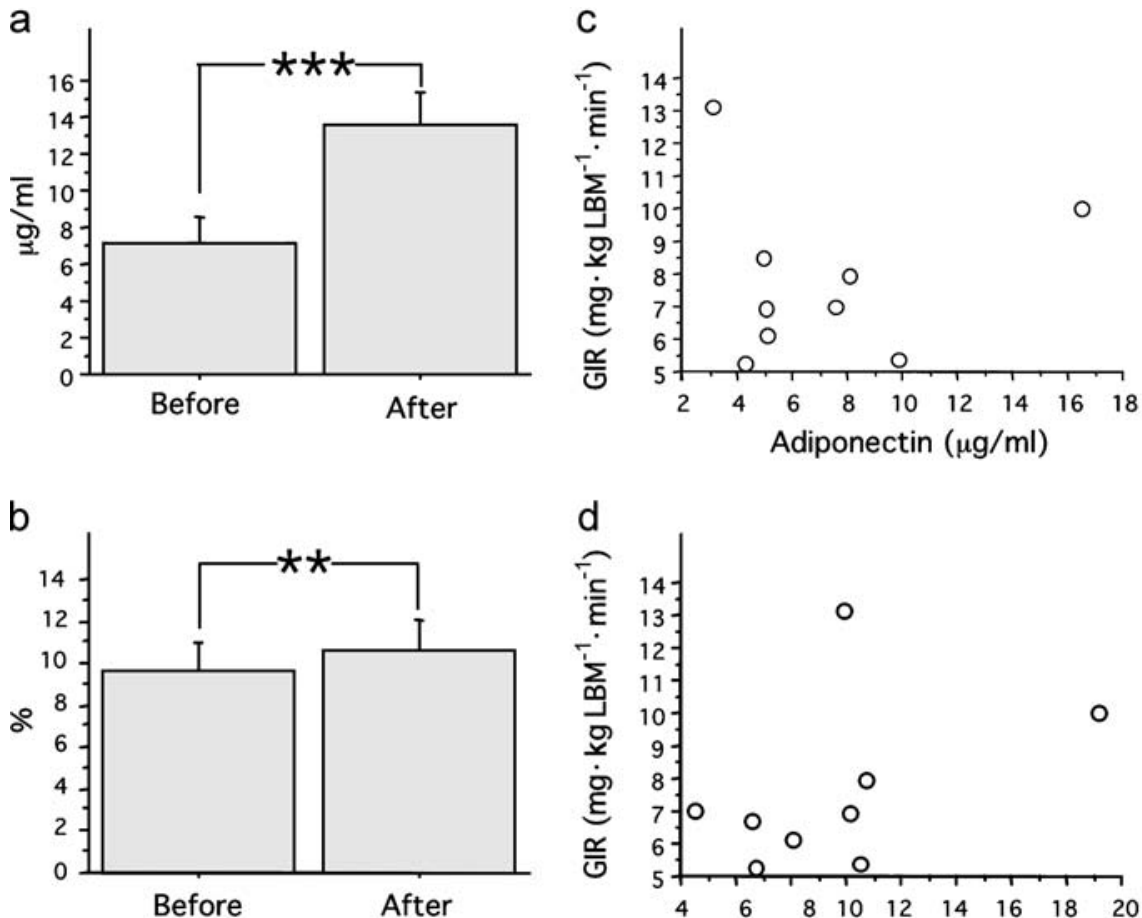
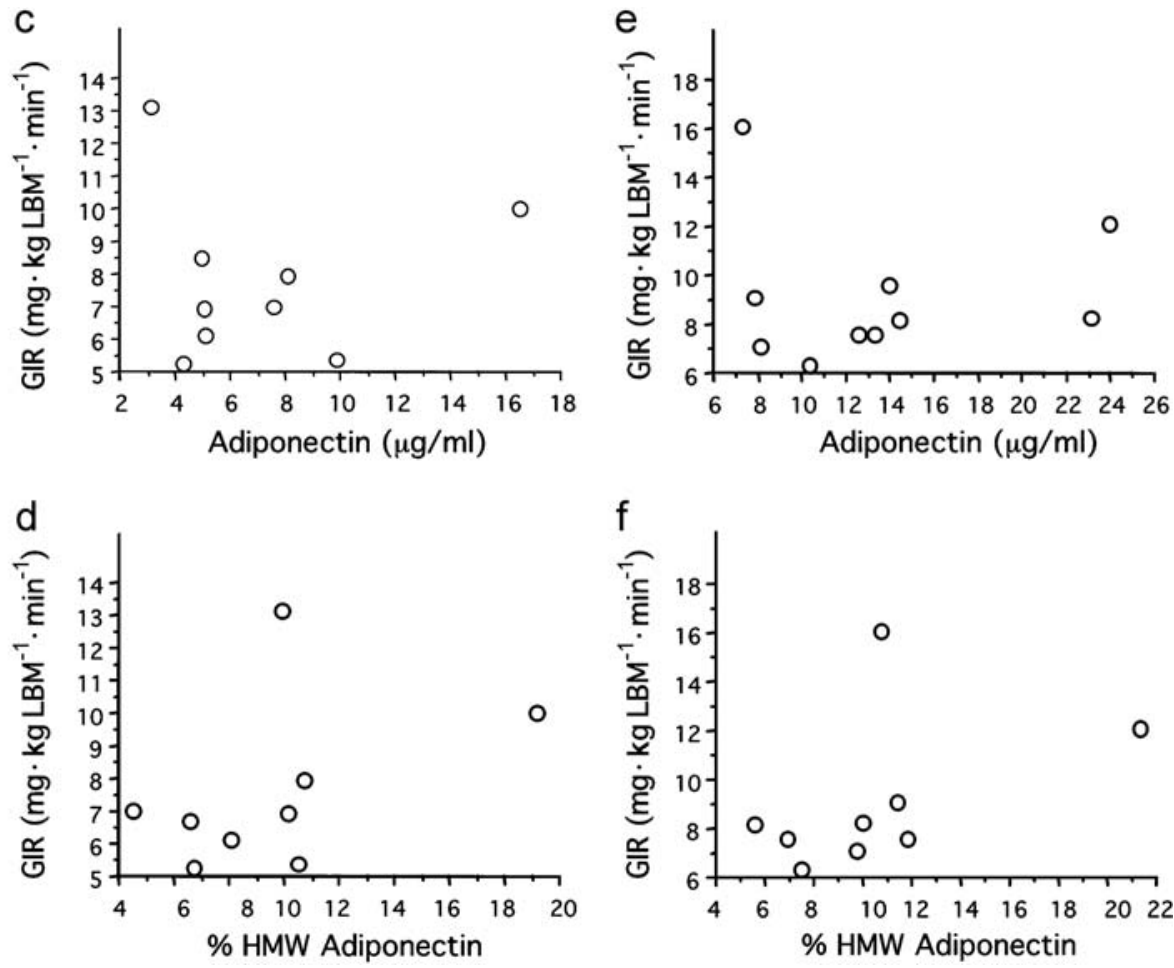

Fig. 1 Circulating total (a) and relative amounts of HMW (b) adiponectin before and after thiazolidinedione treatment. Correlation analyses between circulating and relative levels and insulin sensitivity measured as the glucose infusion rate (GIR) during a eug- lycaemic-hyperinsulinaemic clamp is shown before $(\mathbf{c}, \mathbf{d})$ and after (e, f) thiazolidinedione treatment, respectively. $* * p<0.01$, $* * * p<0.001$. HMW, high-molecular weight following pioglitazone, and the total circulating levels of adiponectin.

Adipose cell differentiation The expression of several genes before and after pioglitazone treatment was examined in isolated adipose cells (Table 2) as well as in intact biopsies. In general, similar effects were found. In all subjects, mRNA levels of adiponectin, like circulating levels, increased after treatment, but the magnitude was much smaller $(30 \%, p<0.05)$ (Table 2) and did not correlate with total circulating or HMW adiponectin levels or with insulin sensitivity (data not shown).

The mRNA for another marker of adipocyte differentiation, aP2, was also increased after pioglitazone treatment $(p=0.06)$. However, neither adipose differentiation-related protein nor lipin nor perilipin expression was changed (Table 2, Fig. 2a).

No significant changes were seen in the mRNA levels of the putative adiponectin receptors 1 or 2 (Table 2), and the expression of either receptor did not correlate with total circulating or HMW adiponectin levels or with insulin sensitivity (data not shown). In contrast to adiponectin mRNA, there was no change in the expression level of either AMP-activated kinase alpha subunit 1 or 2 in the isolated adipocytes after 3 weeks of treatment with pioglitazone (Table 2).

GLUT4, $P G C-1$ and liver $X$ receptor- $\alpha$ The mRNA expression of GLUT4 increased $(p<0.01$, Table 2$)$ and this
Table 2 Gene expression in isolated adipocytes

\begin{tabular}{lccl}
\hline & Before treatment & After treatment & $p$ Value \\
\hline Insulin receptor & $1.08 \pm 0.16$ & $1.02 \pm 0.13$ & NS \\
IRS1 & $1.12 \pm 0.19$ & $1.14 \pm 0.11$ & NS \\
IRS2 & $1.53 \pm 0.21$ & $1.49 \pm 0.12$ & NS \\
GLUT4 & $1.16 \pm 0.21$ & $1.67 \pm 0.23$ & $<0.005$ \\
PGC1 & $1.31 \pm 0.31$ & $1.23 \pm 0.21$ & NS \\
LXR $\alpha$ & $0.74 \pm 0.06$ & $0.86 \pm 0.07$ & 0.06 \\
PPAR $\gamma 2$ & $3.12 \pm 0.92$ & $2.88 \pm 0.62$ & NS \\
Adiponectin & $2.08 \pm 0.48$ & $2.51 \pm 0.43$ & $<0.05$ \\
aP2 & $0.87 \pm 0.04$ & $1.00 \pm 0.07$ & 0.06 \\
ADRP & $1.66 \pm 0.19$ & $1.69 \pm 0.18$ & NS \\
Perilipin & $1.82 \pm 0.17$ & $1.81 \pm 0.11$ & NS \\
Lipin & $1.18 \pm 0.18$ & $1.36 \pm 0.29$ & NS \\
AdipoR1 & $2.10 \pm 0.74$ & $2.00 \pm 0.77$ & NS \\
AdipoR2 & $1.61 \pm 0.33$ & $1.70 \pm 0.42$ & NS \\
AMPK $\alpha 1$ & $0.79 \pm 0.27$ & $0.64 \pm 0.15$ & NS \\
AMPK $\alpha 2$ & $0.60 \pm 0.17$ & $0.54 \pm 0.12$ & NS \\
FOXC2 & $2.39 \pm 0.50$ & $2.40 \pm 0.64$ & NS \\
UCP2 & $1.46 \pm 0.23$ & $2.22 \pm 0.31$ & $<0.005$ \\
\hline
\end{tabular}

Values are expressed as mean \pm SEM.

PGC1 PPAR $\gamma$ co-activator $1, L X R \alpha$ liver $\mathrm{X}$ receptor, PPAR 2 peroxisome proliferator-activated receptor $\gamma 2$, ap 2 adipocyte $\mathrm{P} 2$, $A D R P$ adipose differentiation-related protein, AdipoR1/2 adiponectin receptor $1 / 2, A M P K$ AMP-activated kinase, FOXC2 forkheadox $\mathrm{C} 2, \mathrm{UCP} 2$ uncoupling protein 2 
a
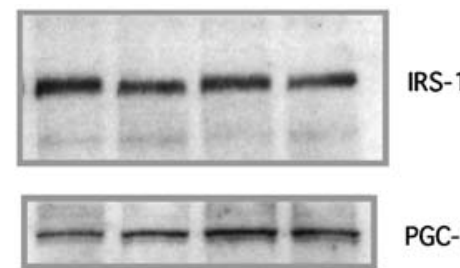

PGC-1
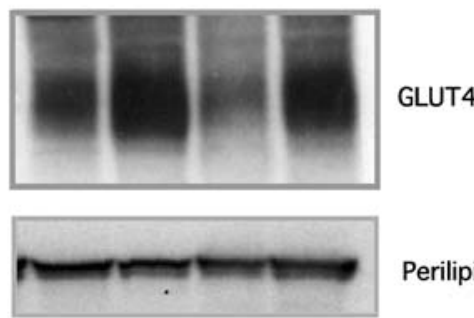

Perilipin

B A B A

b
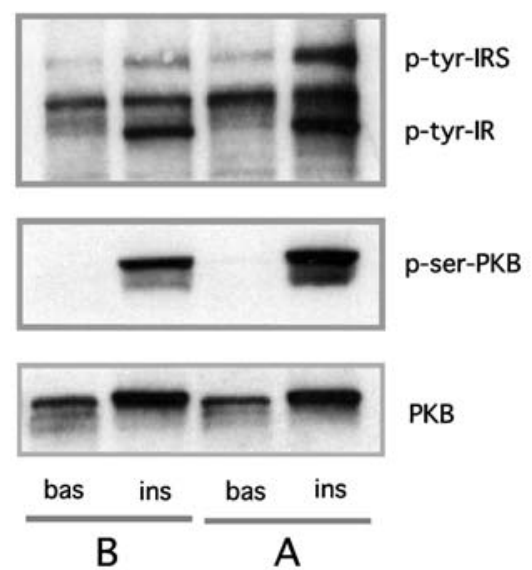

PKB
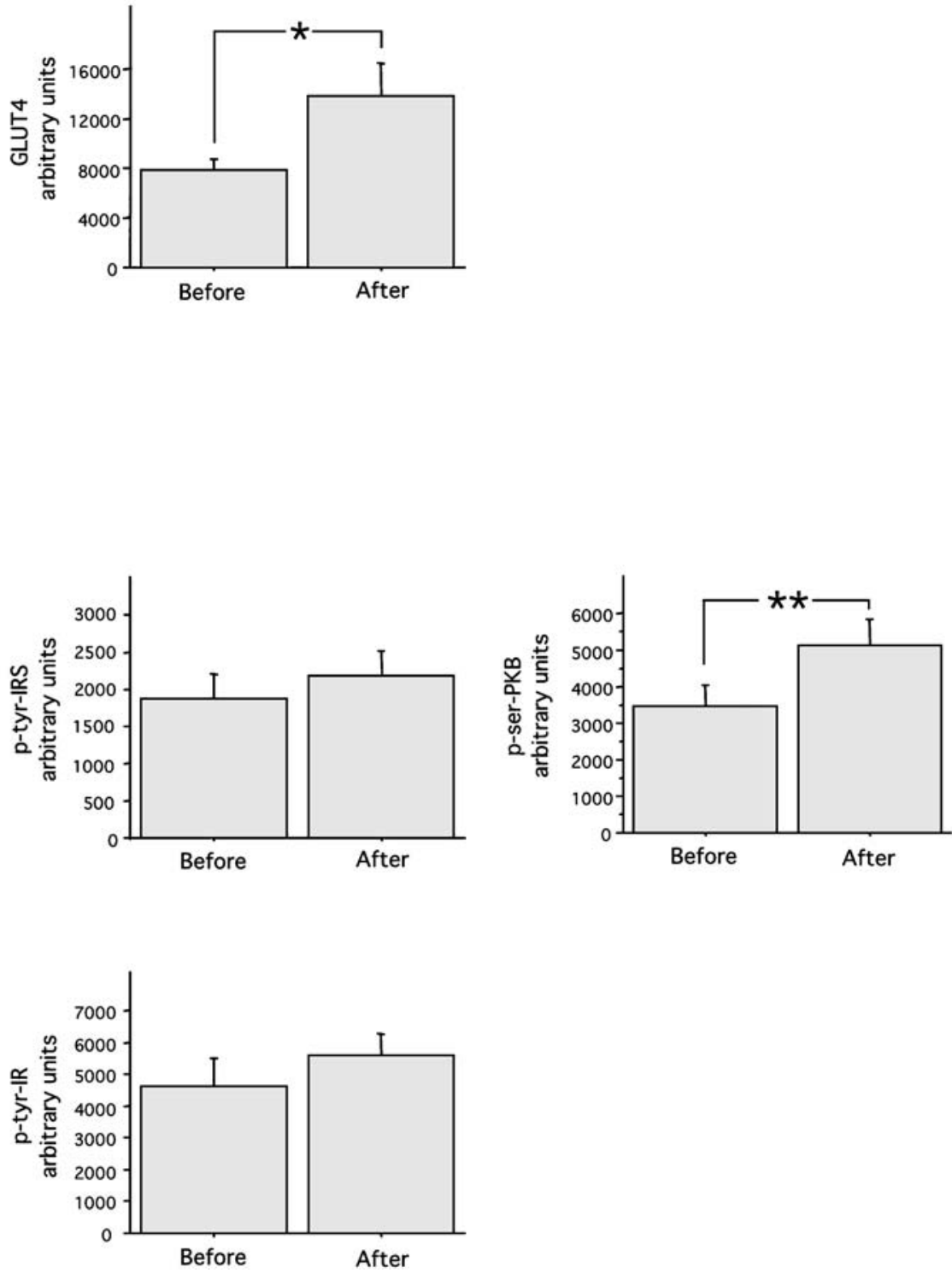

Fig. 2 a Representative Western blots of IRS-1, PGC-1, GLUT4 and perilipin performed on isolated cells from two individuals, before (B) and after (A) treatment with thiazolidinedione. Bars show the densitometry scanning of GLUT4 protein expression $(n=8)$. b Representative Western blots of insulin-stimulated phosphorylation

was accompanied by an identical increase in GLUT4 protein expression $(72 \%, p<0.05)$ (Fig. 2a). The mRNA expression of GLUT4 correlated positively with that of adiponectin, both in isolated adipose cells $\left(r^{2}=0.43\right.$, $p=0.07$; Fig. $3 \mathrm{a})$ and in adipose tissue $\left(r^{2}=0.67, p<0.01\right.$; Fig. 3b), but there was no significant correlation between either plasma total or HMW adiponectin and the expression of GLUT4 mRNA or protein (data not shown). PGC1 is expressed in human white adipose cells and the expression level is reduced in insulin resistance [21]. PGC-1 has also been found to increase GLUT4 expression in skeletal muscle [29]. However, there was no change in $P G C-1$ gene or protein expression in the adipose cells of the insulin receptor (IR), IRS and PKB/Akt protein and serine phosphorylation performed on cells from one individual, before $(\mathrm{B})$ and after (A) treatment with thiazolidinedione $(n=4)$. Bars show the densitometry scanning of the respective bands. Values are expressed as means \pm SEM. $* p<0.05, * * p<0.01$ when comparing before and after pioglitazone treatment (Table 2, Fig. 2a). Another transcription factor which has been shown to increase GLUT4 expression in adipose cells is liver $\mathrm{X}$ receptor $(\mathrm{LXR} \alpha)$ [30]. Interestingly, $\mathrm{LXR} \alpha$ expression was increased after pioglitazone in isolated adipose cells (Table 2), as well as in intact tissue $(p<0.01)$.

Forkheadox C2 and uncoupling protein 2 We also examined mRNA levels of these proteins, which are considered to be important for energy expenditure. Forkheadox $\mathrm{C} 2$ remained unchanged while uncoupling protein 2 (UCP2) was markedly increased in isolated adipose cells (Table 2) and in adipose tissue $(p<0.05)$. 
Fig. 3 Correlation analysis of GLUT4 and adiponectin mRNA measured by real-time RT-PCR in isolated adipose cells (a) and adipose tissue (b)

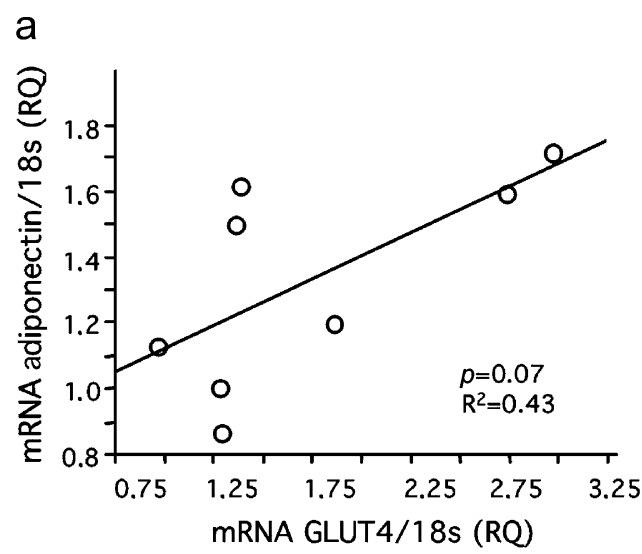

b

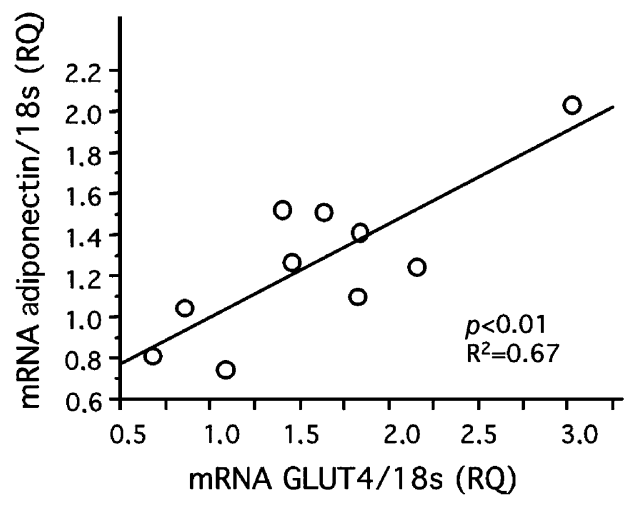

Insulin signalling in the adipose cells The effect of insulin, when added for $15 \mathrm{~min}$ to the cells in vitro, on the downstream signalling, which was measured as serine phosphorylation of $\mathrm{PKB} / \mathrm{Akt}$, as well as the upstream tyrosine phosphorylation of the insulin receptor (IR) and the IRS, was examined in four individuals from whom enough tissue was obtained both before and after treatment with pioglitazone. As shown in Fig. 2, p-ser-PKB/Akt was significantly increased after thiazolidinedione and this was associated with increased tyrosine phosphorylation of IR and IRS (Fig. 2b). The increased p-ser-PKB/Akt was not due to increased protein expression, nor was IR or IRS-1 gene expression (Table 2) or IRS-1 protein increased (Fig. 2a). We also examined whether IRS-2 was increased, but no such consistent effect was found after the short-term pioglitazone treatment (data not shown).

Thus, the increased downstream activation of $\mathrm{PKB} / \mathrm{Akt}$ following pioglitazone could not be attributed to effects on protein expression of $\mathrm{PKB} / \mathrm{Akt}$ or the expression of upstream signalling molecules. We then examined whether pioglitazone changed the expression of the phosphotyrosine phosphatase (PTP)-1B and PTP-1D. However, the mRNA levels of both these phosphatases remained unchanged (data not shown).

Table 3 Gene expression of inflammatory markers in adipose tissue

\begin{tabular}{lcrl}
\hline & Before treatment & After treatment & $p$ Value \\
\hline IL6 & $0.29 \pm 0.06$ & $0.23 \pm 0.05$ & NS \\
Gp130 & $0.87 \pm 0.19$ & $0.96 \pm 0.25$ & NS \\
SOCS1 & $0.58 \pm 0.08$ & $0.60 \pm 0.07$ & NS \\
SOCS3 & $0.11 \pm 0.03$ & $0.10 \pm 0.03$ & NS \\
TNF $\alpha$ & $1.09 \pm 0.15$ & $1.20 \pm 0.14$ & NS \\
IL8 & $0.20 \pm 0.04$ & $0.16 \pm 0.03$ & 0.06 \\
CD68 & $1.06 \pm 0.11$ & $1.32 \pm 0.13$ & 0.06 \\
MAC1 & $0.93 \pm 0.11$ & $1.00 \pm 0.11$ & NS \\
MCP1 & $0.50 \pm 0.12$ & $0.46 \pm 0.04$ & NS \\
EMR1 & $0.76 \pm 0.11$ & $0.88 \pm 0.08$ & NS \\
\hline
\end{tabular}

Values are expressed as mean \pm SEM.

SOCS1/3 Suppressors of cytokine signalling 1/3, CD68 macrophage antigen $\mathrm{CD} 68, \mathrm{MACl}$ macrophage antigen alpha polypeptide, $M C P 1$ monocyte chemoattractant protein-1, EMR 1 egf-like module containing, mucin-like, hormone receptor-like 1
Inflammatory markers in the adipose tissue The gene expression of several pro-inflammatory cytokines known to be increased in states of insulin resistance, such as IL-6, $\mathrm{TNF} \alpha$ and IL-8, was measured in intact adipose tissue (Table 3) and in isolated adipose cells. We also measured the mRNA levels of proteins involved in cytokine signalling (Table 3 ).

None of these genes changed their expression levels significantly after pioglitazone either in the isolated adipose cells (not shown) or in the adipose tissue, although there was a trend for expression of IL- 8 to be decreased in the adipose tissue ( $p=0.06$; Table 3 ).

The inflammatory process that occurs in adipose tissue in obesity is also reflected by an elevation of macrophage attractants and markers [14] suggesting that adipose tissue becomes inflamed in obesity [15]. We, therefore, also measured specific markers for macrophage infiltration in the adipose tissue before and after treatment. However, no change was seen in either the macrophage surface markers (macrophage antigen alpha polypeptide, egf-like module containing, mucin-like, hormone receptor-like 1 or macrophage antigen $\mathrm{CD} 68$ ) or in monocyte chemoattractant protein-1 (MCP1), a member of the small inducible cytokines family, which, like IL-8, can play an important role in the recruitment of macrophages (Table 3 ).

\section{Discussion}

Previous studies from this laboratory have shown an early association between adipose tissue dysfunction and insulin resistance [17-21, 31].

In the present study, we examined whether thiazolidinedione treatment improved some, or all, of the identified markers of adipose tissue dysfunction in this group of individuals. Since the subjects were non-diabetic, confounding effects of lowering the degree of glycaemia would not be expected.

The salient results of the present study are: (1) insulin sensitivity was improved in the non-diabetic subjects after only 3 weeks of treatment with pioglitazone; (2) this improvement was seen in the absence of any reduction in the circulating levels of NEFA or other lipids; (3) circulating adiponectin levels, including HMW adiponectin, 
were consistently increased; (4) markers of terminal differentiation of the adipose cells, like aP2 and adiponectin, were increased; (5) GLUT4, LXR $\alpha$ and UCP2 were increased while no difference was seen in IRS-1, PGC-1 or the markers of adipose tissue infiltration of inflammatory cells; and (6) insulin-induced intracellular signalling was improved.

Taken together, these findings are consistent with an improved terminal differentiation of the adipose cells and/ or an increased recruitment of pre-adipocytes along the adipose lineage. The small difference in mean adipose cell size seen after 3 weeks tends to favour an important role for the former possibility. Surprisingly, IRS-1 expression, like PGC-1, was not increased by the thiazolidinedione, suggesting the involvement of additional mechanisms than merely impaired differentiation of the adipose cells.

In contrast to IRS-1 and PGC-1, thiazolidinedione treatment was associated with a substantial and consistent increase in the expression of GLUT4 mRNA and protein. Interestingly, a significant correlation was found between the expression of GLUT4 and adiponectin, both in isolated adipocytes and in adipose tissue biopsies, supporting an important role for enhanced terminal differentiation of the adipose cells.

Although the insulin-stimulated glucose uptake in adipose tissue only accounts for $\sim 10 \%$ of total glucose disposal, GLUT4 expression levels in adipose cells appear to play a prominent role for whole-body insulin sensitivity, since adipose-selective ablation of the GLUT4 gene impairs insulin action in the liver and skeletal muscle in vivo [32]. This finding clearly indicates that factors secreted from the adipose tissue influence liver and skeletal muscle insulin sensitivity.

Previous studies of the effect of PPAR $\gamma$ agonists on the expression of GLUT4 in the adipose cells have been contradictory [33-36]. However, a recent study has shown that the PPAR/retinoic X receptor heterodimer exerts an inhibitory effect on GLUT4 promoter activity, and that thiazolidinedione binding to the receptor alleviates this repression [37]. However, other mechanisms could also be involved. GLUT4 expression is induced by the PPAR $\gamma$ coactivator PGC-1, at least in skeletal muscles [29]. In addition, a recent study showed that agonists for the LXR $\alpha$ receptor increased GLUT4 expression in 3T3-L1 adipocytes [30]. $\mathrm{LXR} \alpha$, in contrast to PGC-1, was increased by thiazolidinedione. Thus, the present data would support a role of $\operatorname{LXR} \alpha$ in increasing GLUT4 expression in response to thiazolidinedione. It has previously been shown that $L X R \alpha$ is a gene responsive to PPAR response element [38]. It should be emphasised that activation of $\mathrm{LXR} \alpha$, in contrast to PPAR $\gamma$, does not enhance the terminal differentiation of adipose cells, but it does augment lipid accretion [39]. However, such cross talk between these nuclear receptors could contribute to the multitude of effects induced by thiazolidinedione.

We found no significant correlation between circulating adiponectin levels and degree of insulin sensitivity in the present study. This somewhat unexpected finding is probably due to the small number of individuals studied and/or their fairly narrow range of insulin sensitivity. Most previous studies have included larger groups with greater variation in insulin sensitivity.

However, circulating adiponectin levels increased in all subjects after treatment with pioglitazone. This finding is in line with previous publications that thiazolidinedione increases plasma adiponectin levels in obese and in type 2 diabetic patients, as well as in normal subjects to a similar extent. This is accompanied by improvements in different metabolic variables in obese and diabetic, but not in lean insulin-sensitive subjects [40]. This discrepancy has been recently elucidated by the finding that it is not the absolute amount, but rather the distribution of low- and highmolecular weight adiponectin that is important for improved insulin sensitivity in the liver [11]. We also found HMW adiponectin to be increased, but no correlation was seen with the improvement in whole-body insulin sensitivity measured as glucose disposal rate. Since the liver seems to be the primary site of action for HMW adiponectin, this finding was not unexpected and is in agreement with the recent study [11].

Since perilipin is induced by PPAR $\gamma$ agonists [41], such an effect of thiazolidinedione could account for the reduced NEFA levels that have been frequently reported $[42,43]$. However, perilipin mRNA and protein levels were not changed by thiazolidinedione in the present study nor were the NEFA levels changed. Thus, it is possible that this effect of thiazolidinedione depends on the presence of obesity, since perilipin expression seems to be reduced in the obese state [44]. Irrespective of mechanisms, the present study clearly shows that insulin sensitivity is improved by thiazolidinedione before any changes can be seen in circulating NEFA levels.

Growing evidence has indicated an association between insulin resistance and inflammation both systemically and in the adipose tissue. Pro-inflammatory markers, such as TNF $\alpha$ and IL- 6 are overexpressed in adipose tissue in obesity [45, 46], and in non-obese states of insulin resistance [47] IL-6 has also been shown to reduce the expression of $\mathrm{aP} 2$, adiponectin and PPAR $\gamma 2[16,48]$, markers of terminal adipocyte differentiation. There were no significant changes in the expression of either cytokine in the present study, which makes it unlikely that the increase in adiponectin and aP2 following thiazolidinedione treatment was due to an amelioration of local inflammation. However, it should be emphasised that the subjects in the present study were non-obese.

The inflammatory process in the adipose tissue of obese and insulin-resistant individuals is not only characterised by elevation of inflammatory cytokines in the adipose cells, but also by the infiltration of inflammatory cells that may play a role in the insulin resistance [13, 14].

The adipocyte-secreted MCP-1 was recently demonstrated to be induced by IL- 6 and TNF $\alpha$ and to decrease insulin-stimulated glucose uptake as well as the expression of GLUT4, aP2 and PPAR $\gamma$ [49]. Furthermore, MCP-1 and other macrophage-related genes were reduced in $o b / o b$ mice following thiazolidinedione treatment [14]. However, we did not find any significant effect of thiazolidinedione 
on several macrophage markers in our non-obese individuals. This is consistent with the concept that the insulinsensitising effect of thiazolidinedione is not necessarily dependent on the anti-inflammatory effect of these agents, but that this may be of additional importance in the obese state.

Thiazolidinedione increased the expression of UCP-2, which is in agreement with some [50] but not all [51] previously published findings. However, the physiological effect of the increased UCP-2 mRNA levels following thiazolidinedione is currently unclear and requires further examination.

Finally, the present study also shows that the insulin intracellular signalling cascade was improved by shortterm treatment with thiazolidinedione. This was evident both from the increased tyrosine phosphorylation of the IR and IRS, and from the serine phosphorylation of PKB/Akt.

However, the mechanism for this remains obscure since there was no up-regulation of these proteins nor could we document a change in the gene expression of PTP-1C or PTP-1D. Insufficient availability of tissue prevented us from examining directly whether the activity of these or other tyrosine phosphatases was changed, which, in fact, would appear likely.

In conclusion, the present study shows for the first time that short-term treatment with pioglitazone leads to improved insulin sensitivity in non-obese and insulinresistant individuals in the absence of any changes in circulating NEFA and other lipid levels. Several markers of adipose cell differentiation were augmented, supporting the concept that insulin resistance in these non-obese and nondiabetic subjects was associated with an impaired terminal differentiation of the adipose cells. In addition, the upstream intracellular signalling cascade for insulin was improved but the precise mechanism for this remains unclear. The increased expression of LXR $\alpha$ adds another dimension whereby thiazolidinedione can improve insulin action.

Acknowledgements This study was supported by grants from the Swedish Research Council (K2001-72X-03506-30B), the Swedish Diabetes Association, the Sonya Hedenbratt Memorial Fund, the IngaBritt and Arne Lundberg Foundation, the Novo-Nordisk Foundation and the Torsten and Ragnar Söderberg Foundation.

Duality of interest: none.

\section{References}

1. Hevener AL, He W, Barak Y et al (2003) Muscle-specific Pparg deletion causes insulin resistance. Nat Med 9:1491-1497

2. Norris AW, Chen L, Fisher SJ et al (2003) Muscle-specific PPARgamma-deficient mice develop increased adiposity and insulin resistance but respond to thiazolidinediones. J Clin Invest 112:608-618

3. Miyazaki Y, Mahankali A, Matsuda M et al (2002) Effect of pioglitazone on abdominal fat distribution and insulin sensitivity in type 2 diabetic patients. J Clin Endocrinol Metab 87:2784-2791

4. Fujiwara T, Yoshioka S, Yoshioka T, Ushiyama I, Horikoshi H (1988) Characterization of new oral antidiabetic agent CS-045. Studies in KK and $o b / o b$ mice and Zucker fatty rats. Diabetes 37:1549-1558
5. Okuno A, Tamemoto H, Tobe K et al (1998) Troglitazone increases the number of small adipocytes without the change of white adipose tissue mass in obese Zucker rats. J Clin Invest 101:1354-1361

6. De Souza CJ, Eckhardt M, Gagen K et al (2001) Effects of pioglitazone on adipose tissue remodeling within the setting of obesity and insulin resistance. Diabetes 50:1863-1871

7. Boden G, Cheung P, Mozzoli M, Fried SK (2003) Effect of thiazolidinediones on glucose and fatty acid metabolism in patients with type 2 diabetes. Metabolism 52:753-759

8. Scherer PE, Williams S, Fogliano M, Baldini G, Lodish HF (1995) A novel serum protein similar to C1q, produced exclusively in adipocytes. J Biol Chem 270:26746-26749

9. Maeda K, Okubo K, Shimomura I, Funahashi T, Matsuzawa Y, Matsubara K (1996) cDNA cloning and expression of a novel adipose specific collagen-like factor, apM1 (adipose most abundant gene transcript 1). Biochem Biophys Res Commun 221:286-289

10. Hu E, Liang P, Spiegelman BM (1996) AdipoQ is a novel adipose-specific gene dysregulated in obesity. J Biol Chem 271:10697-10703

11. Pajvani UB, Hawkins M, Combs TP et al (2004) Complex distribution, not absolute amount of adiponectin, correlates with thiazolidinedione-mediated improvement in insulin sensitivity. J Biol Chem 279:12152-12162

12. Pickup JC, Mattock MB, Chusney GD, Burt D (1997) NIDDM as a disease of the innate immune system: association of acutephase reactants and interleukin-6 with metabolic syndrome $\mathrm{X}$. Diabetologia 40:1286-1292

13. Weisberg SP, McCann D, Desai M, Rosenbaum M, Leibel RL, Ferrante AW Jr (2003) Obesity is associated with macrophage accumulation in adipose tissue. J Clin Invest 112:1796-1808

14. Xu H, Barnes GT, Yang Q et al (2003) Chronic inflammation in fat plays a crucial role in the development of obesity-related insulin resistance. J Clin Invest 112:1821-1830

15. Wellen KE, Hotamisligil GS (2003) Obesity-induced inflammatory changes in adipose tissue. J Clin Invest 112:1785-1788

16. Sopasakis VR, Sandqvist M, Gustafson B et al (2004) High local concentrations and effects on differentiation implicate interleukin-6 as a paracrine regulator. Obes Res 12:454-460

17. Rondinone CM, Wang LM, Lonnroth P, Wesslau C, Pierce JH, Smith U (1997) Insulin receptor substrate (IRS) 1 is reduced and IRS-2 is the main docking protein for phosphatidylinositol 3-kinase in adipocytes from subjects with non-insulin-dependent diabetes mellitus. Proc Natl Acad Sci U S A 94:41714175

18. Carvalho E, Jansson PA, Nagaev I, Wenthzel AM, Smith U (2001) Insulin resistance with low cellular IRS-1 expression is also associated with low GLUT4 expression and impaired insulin-stimulated glucose transport. FASEB J 15:1101-1103

19. Jansson PA, Pellme F, Hammarstedt A et al (2003) A novel cellular marker of insulin resistance and early atherosclerosis in humans is related to impaired fat cell differentiation and low adiponectin. FASEB J 17:1434-1440

20. Yang X, Jansson PA, Nagaev I et al (2004) Evidence of impaired adipogenesis in insulin resistance. Biochem Biophys Res Commun 317:1045-1051

21. Hammarstedt A, Jansson PA, Wesslau C, Yang X, Smith U (2003) Reduced expression of PGC-1 and insulin-signaling molecules in adipose tissue is associated with insulin resistance. Biochem Biophys Res Commun 301:578-582

22. Krotkiewski M, Bjorntorp P, Sjostrom L, Smith U (1983) Impact of obesity on metabolism in men and women. Importance of regional adipose tissue distribution. J Clin Invest 72:1150-1162

23. Lukaski HC, Bolonchuk WW, Hall CB, Siders WA (1986) Validation of tetrapolar bioelectrical impedance method to assess human body composition. J Appl Physiol 60:1327-1332

24. DeFronzo RA, Tobin JD, Andres R (1979) Glucose clamp technique: a method for quantifying insulin secretion and resistance. Am J Physiol 237:E214-E223 
25. Attvall S, Eriksson BM, Fowelin J, von Schenck H, Lager I, Smith U (1987) Early posthypoglycemic insulin resistance in man is mainly an effect of beta-adrenergic stimulation. J Clin Invest 80:437-442

26. Axelsen M, Smith U, Eriksson JW, Taskinen MR, Jansson PA (1999) Postprandial hypertriglyceridemia and insulin resistance in normoglycemic first-degree relatives of patients with type 2 diabetes. Ann Intern Med 131:27-31

27. Smith U, Sjostrom L, Bjornstorp P (1972) Comparison of two methods for determining human adipose cell size. J Lipid Res $13: 822-824$

28. Smith U, Gogg S, Johansson A, Olausson T, Rotter V, Svalstedt B (2001) Thiazolidinediones (PPARgamma agonists) but not PPARalpha agonists increase IRS-2 gene expression in 3T3-L1 and human adipocytes. FASEB J 15:215-220

29. Michael LF, Wu Z, Cheatham RB et al (2001) Restoration of insulin-sensitive glucose transporter (GLUT4) gene expression in muscle cells by the transcriptional coactivator PGC-1. Proc Natl Acad Sci U S A 98:3820-3825

30. Dalen KT, Ulven SM, Bamberg K, Gustafsson JA, Nebb HI (2003) Expression of the insulin-responsive glucose transporter GLUT4 in adipocytes is dependent on liver X receptor alpha. J Biol Chem 278:48283-48291

31. Carvalho E, Jansson PA, Axelsen M et al (1999) Low cellular IRS 1 gene and protein expression predict insulin resistance and NIDDM. FASEB J 13:2173-2178

32. Abel ED, Peroni O, Kim JK et al (2001) Adipose-selective targeting of the GLUT4 gene impairs insulin action in muscle and liver. Nature 409:729-733

33. Furuta M, Yano Y, Gabazza EC et al (2002) Troglitazone improves GLUT4 expression in adipose tissue in an animal model of obese type 2 diabetes mellitus. Diabetes Res Clin Pract 56:159-171

34. Hallakou S, Doare L, Foufelle F et al (1997) Pioglitazone induces in vivo adipocyte differentiation in the obese Zucker $f a$ / fa rat. Diabetes 46:1393-1399

35. Long SD, Pekala PH (1996) Regulation of GLUT4 gene expression by arachidonic acid. Evidence for multiple pathways, one of which requires oxidation to prostaglandin E2. J Biol Chem 271:1138-1144

36. Ciaraldi TP, Kong AP, Chu NV et al (2002) Regulation of glucose transport and insulin signaling by troglitazone or metformin in adipose tissue of type 2 diabetic subjects. Diabetes $51: 30-36$

37. Armoni M, Kritz N, Harel C et al (2003) Peroxisome proliferator-activated receptor-gamma represses GLUT4 promoter activity in primary adipocytes, and rosiglitazone alleviates this effect. J Biol Chem 278:30614-30623

38. Laffitte BA, Joseph SB, Walczak R et al (2001) Autoregulation of the human liver X receptor alpha promoter. Mol Cell Biol $21: 7558-7568$
39. Hummasti S, Laffitte BA, Watson MA et al (2004) Liver X receptors are regulators of adipocyte gene expression but not differentiation: identification of apoD as a direct target. J Lipid Res 45:616-625

40. Yu JG, Javorschi S, Hevener AL et al (2002) The effect of thiazolidinediones on plasma adiponectin levels in normal, obese, and type 2 diabetic subjects. Diabetes 51:2968-2974

41. Dalen KT, Schoonjans K, Ulven SM et al (2004) Adipose tissue expression of the lipid droplet-associating proteins S3-12 and perilipin is controlled by peroxisome proliferator-activated receptor-gamma. Diabetes 53:1243-1252

42. Ghazzi MN, Perez JE, Antonucci TK et al (1997) Cardiac and glycemic benefits of troglitazone treatment in NIDDM. The Troglitazone Study Group. Diabetes 46:433-439

43. Chaput E, Saladin R, Silvestre M, Edgar AD (2000) Fenofibrate and rosiglitazone lower serum triglycerides with opposing effects on body weight. Biochem Biophys Res Commun 271:445-450

44. Mottagui-Tabar S, Ryden M, Lofgren P et al (2003) Evidence for an important role of perilipin in the regulation of human adipocyte lipolysis. Diabetologia 46:789-797

45. Hotamisligil GS, Arner P, Caro JF, Atkinson RL, Spiegelman BM (1995) Increased adipose tissue expression of tumor necrosis factor-alpha in human obesity and insulin resistance. $\mathrm{J}$ Clin Invest 95:2409-2415

46. Mohamed-Ali V, Goodrick S, Rawesh A et al (1997) Subcutaneous adipose tissue releases interleukin-6, but not tumor necrosis factor-alpha, in vivo. J Clin Endocrinol Metab $82: 4196-4200$

47. Rotter V, Nagaev I, Smith U (2003) Interleukin-6 (IL-6) induces insulin resistance in 3T3-L1 adipocytes and is, like IL8 and tumor necrosis factor-alpha, overexpressed in human fat cells from insulin-resistant subjects. J Biol Chem 278:4577745784

48. Lagathu C, Bastard JP, Auclair M, Maachi M, Capeau J, Caron M (2003) Chronic interleukin-6 (IL-6) treatment increased IL-6 secretion and induced insulin resistance in adipocyte: prevention by rosiglitazone. Biochem Biophys Res Commun 311:372-379

49. Sartipy P, Loskutoff DJ (2003) Monocyte chemoattractant protein 1 in obesity and insulin resistance. Proc Natl Acad Sci U S A 100:7265-7270

50. Aubert J, Champigny O, Saint-Marc P et al (1997) Upregulation of UCP-2 gene expression by PPAR agonists in preadipose and adipose cells. Biochem Biophys Res Commun 238:606-611

51. Emilsson V, O'Dowd J, Wang S et al (2000) The effects of rexinoids and rosiglitazone on body weight and uncoupling protein isoform expression in the Zucker $f a / f a$ rat. Metabolism 49:1610-1615 